\title{
Alleviation effect of arbutin on oxidative stress generated through tyrosinase reaction with L-tyrosine and L-DOPA
}

\author{
Mika Tada ${ }^{1}$, Masahiro Kohno ${ }^{2}$ and Yoshimi Niwano ${ }^{3^{*}}$
}

\begin{abstract}
Background: Hydroxyl radical that has the highest reactivity among reactive oxygen species (ROS) is generated through L-tyrosine-tyrosinase reaction. Thus, the melanogenesis might induce oxidative stress in the skin. Arbutin ( $p$-hydroxyphenyl- $\beta$-D-glucopyranoside), a well-known tyrosinase inhibitor has been widely used for the purpose of skin whitening. The aim of the present study was to examine if arbutin could suppress the hydroxyl radical generation via tyrosinase reaction with its substrates, L-tyrosine and L-DOPA.
\end{abstract}

Results: The hydroxyl radical, which was determined by an electron spin resonance-spin trapping technique, was generated by the addition of not only L-tyrosine but L-DOPA to tyrosinase in a concentration dependent manner. Arbutin could inhibit the hydroxyl radical generation in the both reactions.

Conclusion: It is presumed that arbutin could alleviate oxidative stress derived from the melanogenic pathway in the skin in addition to its function as a whitening agent in cosmetics.

Keywords: Hydroxyl radical, Tyrosinase reaction, Arbutin

\section{Background}

Native human melanin consists of eumelanin and pheomelanin, and eumelanin is found in almost every type of human skin $[1,2]$. In the skin, melanin synthesized in melanocytes, which are located in the basal layer and hair bulbs, transfers to keratinocytes. Melanin in keratinocytes acts as a photoprotector through body coloration and scavenging reactive oxygen species such as superoxide anion and singlet oxygen [3-8]. Despite the photoprotective role of melanin, many cosmetics have been developed to prevent melanin formation in the skin because of aesthetic satisfaction by whitening ability. Of these, inhibitor of tyrosinase, which is a pivotal enzyme for melanin synthesis [9], has been used as a major ingredient of cosmetics [10-14]. Tyrosinase, an enzyme which contains dinuclear copper ions at the active site [15-17], catalyzes two distinct reactions of melanin synthesis [18], the hydroxylation of a monophenol and the conversion of an $o$-diphenol to the corresponding o-quinone, indicating that L-tyrosine is

\footnotetext{
* Correspondence: niwano@m.tohoku.ac.jp

${ }^{3}$ Tohoku University Graduate School of Dentistry, 4-1 Seiryo-machi, Aoba-ku, Sendai 980-8575, Japan

Full list of author information is available at the end of the article
}

hydroxylated to L-DOPA, which is in turn converted to dopaquinone. Our previous study applying electron spin resonance (ESR)-spin trapping method revealed that hydroxyl radicals are generated through L-tyrosine-tyrosinase reaction [19], so that we assumed that dicopper-peroxide intermediates formed during the catalytic process of L-tyrosine to dopaquinone possibly decay to produce the hydroxyl radical through an internal electron transfer from the ligand. This suggests that tyrosinase inhibitors might contribute to alleviate the oxidative damage of the skin by inhibiting hydroxyl radical generation via the enzyme reaction.

Arbutin ( $p$-hydroxyphenyl- $\beta$-D-glucopyranoside), a wellknown tyrosinase inhibitor, which can be extracted from plants, has been widely used for the purpose of skin whitening [20]. Regarding the molecular base mechanisms of arbutin, it was reported that arbutin inhibits not only the oxidation of L-DOPA but the hydroxylation of Ltyrosine [21,22]. With regard to skin-whitening effect of arbutin in relation to melanogenesis, it was reported that arbutin showed no effect on the differentiation of melanocytes while hydroquinone used as a skin-whitening agent downregulated the differentiation [23]. Besides 
tyrosinase inhibition, it was reported that arbutin has anti-inflammatory effect [24], it is expected that arbutin could alleviate inflammation in the skin exposed to ultraviolet (UV) light.

The purpose of the present study was to examine if a tyrosinase inhibitor could suppress the hydroxyl radical generation via tyrosinase reaction with its substrates, Ltyrosine and L-DOPA. In the study, arbutin was used as a representative tyrosinase inhibitor.

\section{Results and discussion}

As reported in our previous study, clear ESR signals were obtained by the L-tyrosine-tyrosinase reaction. Representative ESR spectra obtained from L-tyrosine-tyrosinase reaction with different concentrations of L-tyrosine are summarized in Figure 1a. Typical ESR spectrum (intensity ratio, 1:2:2:1) was assigned to 5,5-dimethyl-1-pyrroline $N$ oxide (DMPO)-OH, a spin adduct derived from hydroxyl radical (hyperfine coupling constant, $\mathrm{aN}=1.49 ; \mathrm{aH}=1.49$ $\mathrm{mT}$ ) as reported in a previous study [19], and signal intensity of DMPO increased with the concentrations of L- tyrosine, which is also supported by the calculated yield of DMPO-OH as shown in Figure $1 \mathrm{~b}$. When L-DOPA was added as a substrate to the reaction mixture containing tyrosinase, similar ESR spectra to those in Figure 1a were obtained (Figure 2a), and the resultant DMPO-OH yield also increased with the concentration of L-DOPA. Figure 3a and $b$ show the representative ESR spectra obtained by the addition of arbutin to the L-tyrosine-tyrosinase solution and the yield of DMPO-OH, respectively. Arbutin clearly lowered the signal intensity of DMPO-OH, suggesting that generation of hydroxyl radicals via L-tyrosine-tyrosinase reaction was inhibited by arbutin in a concentration dependent manner, and IC50 (the concentration which showed $50 \%$ inhibition) calculated by using an approximate formula was $1.7 \mathrm{mM}$. Figure $4 \mathrm{a}$ and $\mathrm{b}$ show the representative ESR spectra obtained by the addition of arbutin to the L-DOPA-tyrosinase solution and the yield of DMPO-OH, respectively. When L-DOPA was used as a substrate, the signal intensity of DMPO-OH was also reduced (IC50 was $2.6 \mathrm{mM}$ ), suggesting that arbutin has an ability to reduce the generation of hydroxyl radicals through tyrosinase

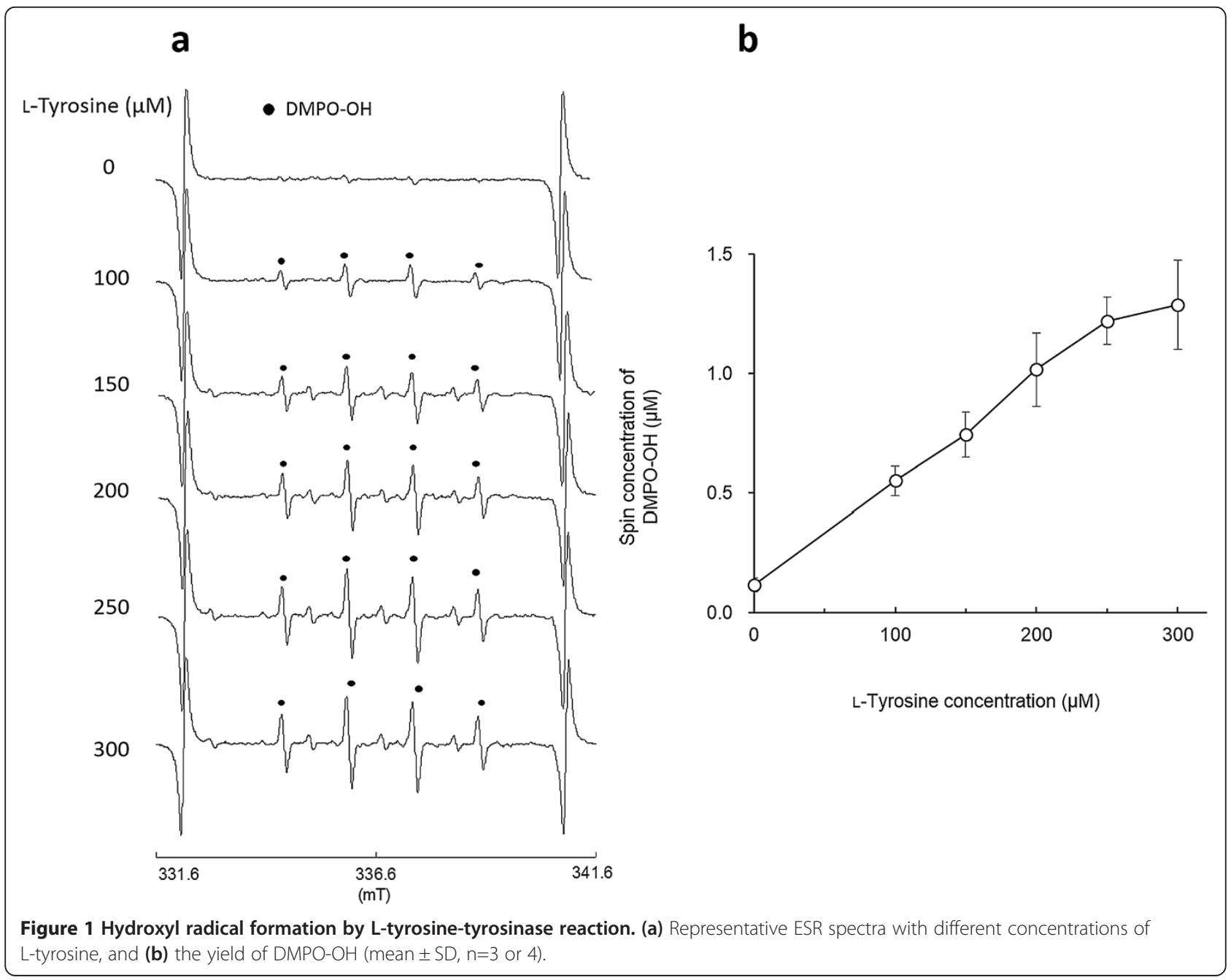




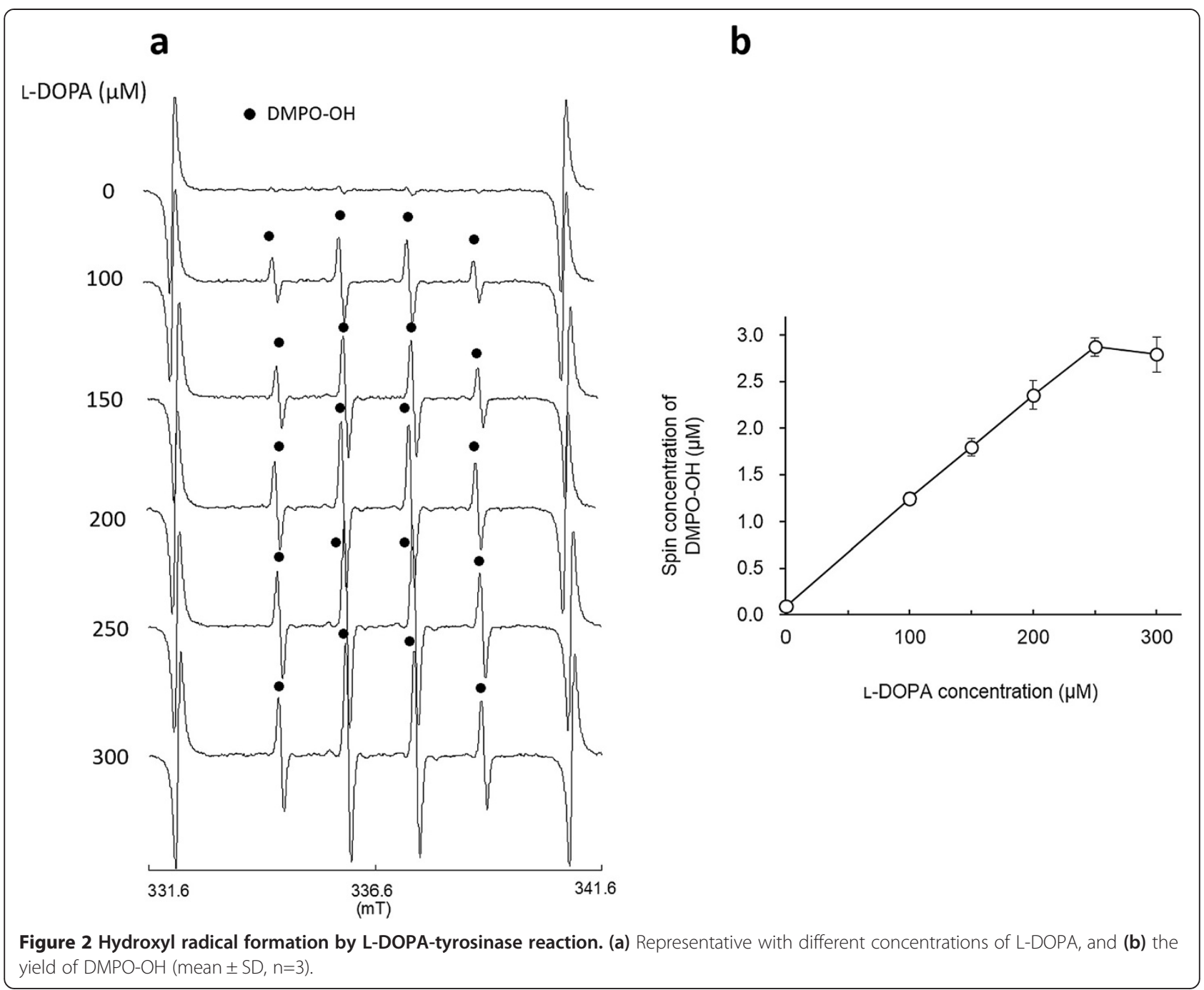

reaction even when L-DOPA was used as a substrate for the enzyme.

Since it was reported that arbutin inhibits not only the oxidation of L-DOPA but the hydroxylation of L-tyrosine $[21,22]$, we hypothesized that arbutin has an ability to suppress the hydroxyl radical formation through the process of tyrosinase reaction to produce melanin. The results of the present study clearly support the hypothesis. Since it was reported that arbutin exhibited antioxidant activity as determined by the 1,1-diphenyl-2-picrylhydrazyl (DPPH) radical scavenging assay but that it was not strong compared to that of antioxidant vitamins, hydroquinone, and caffeic acid $[25,26]$. Thus, we examined the effect of arbutin on the hydroxyl radical generated by a Fenton reaction. Figure 5 shows the representative ESR spectra obtained by the Fenton reaction with $1.78 \mathrm{mM}$ DMPO or $445 \mathrm{mM}$ DMPO. As a result, when $445 \mathrm{mM}$ DMPO that was the same concentration used in the ESR-spin trapping assay described above was used as a spin trapping agent, no reduction in the signal intensity of DMPO-OH was found.
Whilst the reduction in the signal intensity of DMPO-OH was found when the concentration of DMPO was lowered to $1.78 \mathrm{mM}$. Thus, although arbutin reduced DMPO-OH level, the effect was very weak, suggesting that a goodly portion of the reduced amount of hydroxyl radicals observed in the present study was likely attributable to the inhibition of tyrosinase reaction. Regarding the possible involvement of other ROS, since no relevant ESR signal to superoxide anion (DMPO-OOH) was observed in the ESR spectra obtained in the present study and our previous study also revealed that neither superoxide dismutase nor catalase affected the amount of DMPO-OH [19], it is suggested that neither superoxide anion nor hydrogen peroxide is involved in the hydroxyl radical generation by the tyrosinase reaction. As for singlet oxygen, it was reported that singlet oxygen is the main reactive species formed by UVA irradiation on the skin, we will further examine the involvement of singlet oxygen by using an appropriate model with UVA irradiation $[27,28]$. From these, it is presumed that arbutin could alleviate oxidative stress derived 

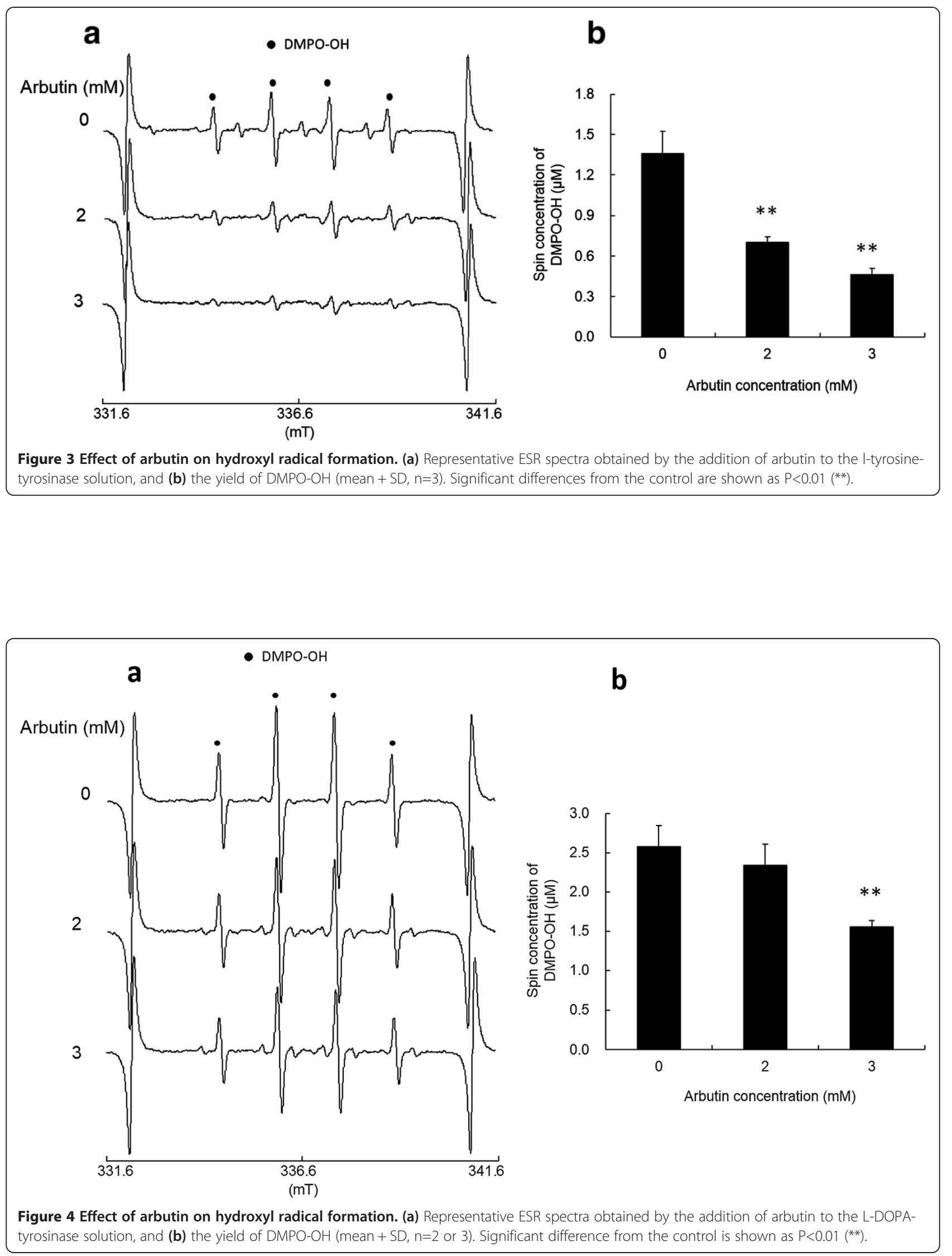


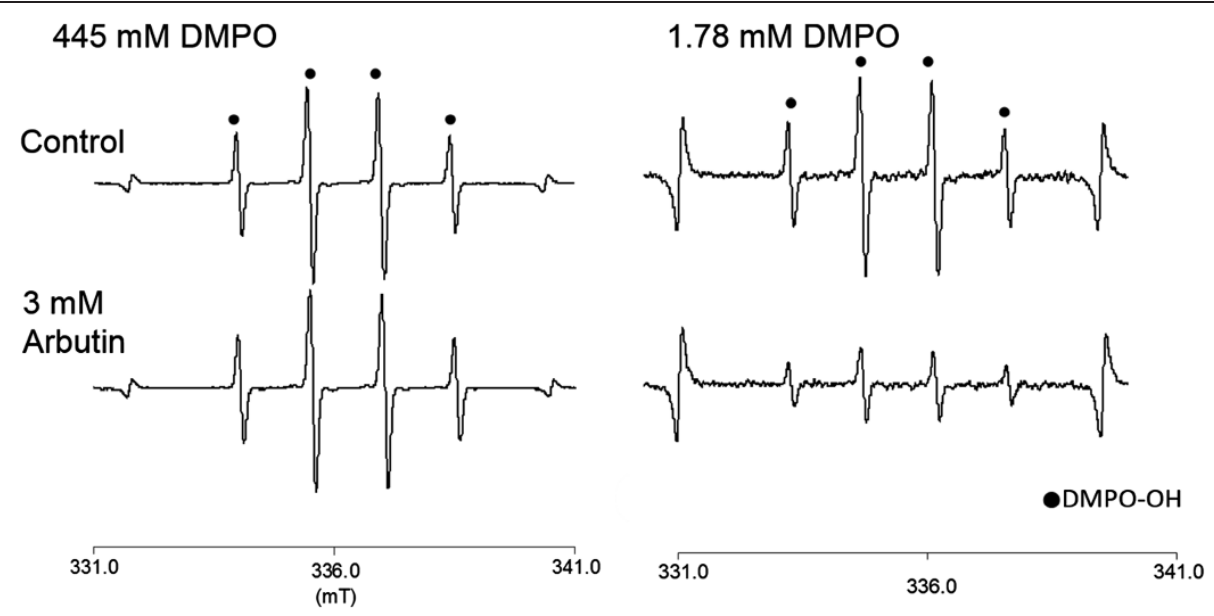

Figure 5 Representative ESR spectra obtained by the addition of arbutin to a Fenton reaction.

from the melanogenic pathway in the skin in addition to its function as a whitening agent in cosmetics. The enzymatic oxidation of L-tyrosine to melanin is of considerable importance because melanin has many functions such as light absorption and scattering in terms of skin protection from photo-aging. On the other side of the coin, the enzyme reaction could cause oxidative damage in the skin via the hydroxyl radical which has the highest reactivity among ROS [29]. Regarding UV-mediated oxidative stress, in addition to singlet oxygen generated upon exposure to UVA [27,28] as described above, it was reported that specific ROS, including superoxide anion, hydrogen peroxide, and hydroxyl radical are enhanced in keratinocytes treated with UVB, and superoxide anion and hydroxyl radical are the main ROS contributing to oxidative stress in the early phase after UVB treatment [30]. Besides ROS formation, UV irradiation also induces melanogenesis. For instance, cocultures of keratinocytes and melanocytes show the importance of cell communication in the melanogenic response through endogenous mediator, nitric oxide upon irradiation by UV [31]. Thus, it seems to be of importance to consider the balance between the UV- and the melanogenesis pathway-mediated oxidative stress because melanogenesis is induced to alleviate the effect of UV. In terms of alleviating oxidative stress in the skin, therefore, combination of a tyrosinase inhibitor such as arbutin and a UV-absorbing agent would be very effective. In the present study, the effect of arbutin was examined in in vitro enzyme reaction system. To validate the alleviation of oxidative stress by arbutin, in vitro melanocyte study as well as in vivo study should be conducted. It was reported that arbutin inhibited the tyrosinase activity of cultured human melanocytes at noncytotoxic concentrations [20], so that we expect that arbutin could alleviate the oxidative stress induced by tyrosinase reaction at cellular level. However, to detect the effect of arbutin, it would be better for the cells to be under the condition of accelerated melanogenesis which could be induced by UV irradiation as reported previously [32]. We will further examine the effect of arbutin on the oxidative stress caused by accelerated melanogenesis in in vitro melanocytes as the next step.

\section{Conclusion}

The hydroxyl radical generation via tyrosinase reaction with either L-tyrosine or L-DOPA was reduced by a tyrosinase inhibitor, arbutin. Thus, it is expected that tyrosinase inhibitors such as arbutin could alleviate oxidative stress derived from the melanogenic pathway in the skin in addition to its function as a whitening agent in cosmetics.

\section{Methods}

\section{Test materials and reagents}

Reagents were purchased from the following sources: LTyrosine, L-DOPA and phosphate buffer solution (PB, $\mathrm{pH}$ 6.5) from Wako Pure Chemicals (Osaka, Japan); tyrosinase (from mushroom) from Sigma-Aldrich Corp. (St. Louis, MO); DMPO from Labotec (Tokyo, Japan); arbutin from LKT Laboratories, Inc. (St. Paul, MN). All other reagents used were of analytical grade.

\section{ESR-spin trapping determinations of hydroxyl radicals generated by tyrosinase reaction with L-tyrosine and L-DOPA}

Tyrosinase was dissolved in PB to be $100 \mathrm{U} / \mathrm{ml}$. L-Tyrosine was dissolved in PB to be $200 \mathrm{mM}$. Then $1 \mathrm{mML}$-tyrosine solution was prepared by mixing $5 \mu \mathrm{l}$ of $200 \mathrm{mML}$-tyrosine solution with $5 \mu \mathrm{l}$ of $1 \mathrm{M} \mathrm{NaOH}$ and $990 \mu \mathrm{l}$ of 0.2 M PB. L-DOPA was also dissolved in $1 \mathrm{M} \mathrm{HCl}$ to be $200 \mathrm{mM}$. Then $1 \mathrm{mML}$-DOPA solution was prepared by mixing $5 \mu \mathrm{l}$ of $200 \mathrm{mM}$ L-DOPA solution with $5 \mu \mathrm{l}$ of $1 \mathrm{M}$ 
$\mathrm{NaOH}$ and $990 \mu \mathrm{l}$ of $0.2 \mathrm{M}$ PB. Formulated concentrate of DMPO $(8.9 \mathrm{M})$ was used. The reaction mixture was prepared to contain different volume of substrate $(1 \mathrm{mM}$ L-tyrosine or $1 \mathrm{mM}$ L-DOPA), $10 \mu \mathrm{l}$ of $8.9 \mathrm{M} \mathrm{DMPO}, 4 \mu \mathrm{l}$ of $100 \mathrm{U} / \mu \mathrm{l}$ tyrosinase and $0.2 \mathrm{M} \mathrm{PB}$ which was added to adjust a total volume of $200 \mu \mathrm{l}$. Immediately after mixing the mixture was transferred to an ESR spectrometry cell, and the ESR measurement was started after $45 \mathrm{~s}$. The measurement conditions of ESR (JES-FA-100, JEOL, Tokyo, Japan) were as follows: field sweep, 330.80-340.80 mT; field modulation frequency, $100 \mathrm{kHz}$; filed modulation width, $0.07 \mathrm{mT}$; amplitude, 400; sweep time, $1 \mathrm{~min}$; time constant, $0.1 \mathrm{~s}$; microwave frequency, $9.430 \mathrm{GHz}$; microwave power, $5 \mathrm{~mW}$. In the study where the effect of arbutin on the hydroxyl radical generation was examined, $100 \mathrm{mM}$ arbutin dissolved in ultrapure water was diluted 10 times with $0.2 \mathrm{M} \mathrm{PB}$. The reaction mixture was prepared to contain different volume of $10 \mathrm{mM}$ arbutin, $60 \mu \mathrm{l}$ of substrate (1 mML-tyrosine or $1 \mathrm{mML}$-DOPA), $10 \mu \mathrm{l}$ of $8.9 \mathrm{M}$ DMPO, $4 \mu \mathrm{l}$ of $100 \mathrm{U} / \mu \mathrm{l}$ tyrosinase and $0.2 \mathrm{M} \mathrm{PB}$ which was added to adjust a total volume of $200 \mu \mathrm{l}$. The concentrations of arbutin used in the study were decided by the enzyme assay for tyrosinase where dopachrome formation was monitored at $475 \mathrm{~nm}$. Arbutin at a concentration of $1.5 \mathrm{mM}$ or more clearly inhibited dopachrome formation (data not shown). To further examine if arbutin has an ability to scavenge directly hydroxyl radicals, effect of arbutin on the hydroxyl radical generated by a Fenton reaction. The reaction mixture was prepared to contain $3 \mathrm{mM}$ arbutin, $0.5 \mathrm{mM} \mathrm{H}_{2} \mathrm{O}_{2}, 0.05 \mathrm{mM} \mathrm{FeSO}_{4}$, and $1.78 \mathrm{mM}$ or $445 \mathrm{mM}$ DMPO, and was subjected to ESR analysis.

\section{Statistical analysis}

In the experiments where the effect of arbutin was examined, statistical significances $(\mathrm{p}<0.05)$ in the yield of DMPO-OH were assessed by Dunnett's multiple comparison test.

\section{Competing interests}

Authors declare that no competing interests.

\section{Authors' contributions}

MT, MK, and YN conceived the study, carried the sample preparation, and ESR determinations. YN drafted the manuscript. All authors read and approved the final manuscript.

\section{Acknowledgments}

This research was supported by the Ministry of Education, Science, Sports and Culture, Japan, Grant-in-Aid for Exploratory Research, 24655159, 2012, and Strategic Research Foundation Grant-in-Aid for Private Universities, S1312001, 2013.

\section{Author details}

${ }^{1}$ Center for General Education, Tohoku Institute of Technology, Sendai, Japan. ${ }^{2}$ Graduate School of Bioscience and Biotechnology, Tokyo Institute of Technology, Yokohama, Japan. ${ }^{3}$ Tohoku University Graduate School of Dentistry, 4-1 Seiryo-machi, Aoba-ku, Sendai 980-8575, Japan.
Received: 12 August 2014 Accepted: 3 October 2014

Published: 9 October 2014

\section{References}

1. Hunt G, Kyne S, Ito S, Wakamatsu K, Todd C, Thody A: Eumelanin and phaeomelanin contents of human epidermis and cultured melanocytes. Pigment Cell Res 1995, 8(4):202-208.

2. Vincensi MR, d'Ischia M, Napolitano A, Procaccini EM, Riccio G, Monfrecola G, Santoianni P, Prota G: Phaeomelanin versus eumelanin as a chemical indicator of ultraviolet sensitivity in fair-skinned subjects at high risk for melanoma: a pilot study. Melanoma Res 1998, 8(1):53-58.

3. Kvam E, Dahle J: Pigmented melanocytes are protected against ultraviolet-A-induced membrane damage. J Invest Dermatol 2003, 121(3):564-569.

4. Yamazaki $F$, Okamoto $H$, Miyauchi-Hashimoto $H$, Matsumura $Y$, Itoh $T$, Tanaka K, Kunisada T, Horio T: XPA gene-deficient, SCF-transgenic mice with epidermal melanin are resistant to UV-induced carcinogenesis. $J$ Invest Dermatol 2004, 123(1):220-228.

5. Wagner JK, Parra EJ, Norton LH, Jovel C, Shriver MD: Skin responses to ultraviolet radiation: effects of constitutive pigmentation, sex, and ancestry. Pigment Cell Res 2002, 15(5):385-390.

6. Ortonne JP: Photoprotective properties of skin melanin. $\mathrm{Br} J$ Dermatol 2002, 146(Suppl 61):7-10.

7. Yamaguchi Y, Takahashi K, Zmudzka BZ, Kornhauser A, Miller SA, Tadokoro T, Berens W, Beer JZ, Hearing VJ: Human skin responses to UV radiation: pigment in the upper epidermis protects against DNA damage in the lower epidermis and facilitates apoptosis. FASEB J 2006, 20(9):1486-1488.

8. Tada M, Kohno M, Niwano Y: Scavenging or quenching effect of melanin on superoxide anion and singlet oxygen. J Clin Biochem Nutr 2010, 46(3):224-228

9. Ito S, Wakamatsu K: Chemistry of mixed melanogenesis-pivotal roles of dopaquinone. Photochem Photobiol 2008, 84(3):582-592.

10. Khazaeli P, Goldoozian R, Sharififar F: An evaluation of extracts of five traditional medicinal plants from Iran on the inhibition of mushroom tyrosinase activity and scavenging of free radicals. Int J Cosmet Sci 2009, 31(5):375-381.

11. Momtaz S, Mapunya BM, Houghton PJ, Edgerly C, Hussein A, Naidoo S, Lal $\mathrm{N}$ : Tyrosinase inhibition by extracts and constituents of Sideroxylon inerme L. stem bark, used in South Africa for skin lightening. J Ethnopharmacol 2008, 119(3):507-512.

12. $\mathrm{Ng} L T, \mathrm{Ko} \mathrm{HH}, \mathrm{Lu}$ TM: Potential antioxidants and tyrosinase inhibitors from synthetic polyphenolic deoxybenzoins. Bioorg Med Chem 2009, 17(13):4360-4366.

13. Nugroho A, Choi JK, Park JH, Lee KT, Cha BC, Park HJ: Two new flavonol glycosides from Lamium amplexicaule $L$. and their in vitro free radical scavenging and tyrosinase inhibitory activities. Planta Med 2009, 75(4):364-366.

14. Wang KH, Lin RD, Hsu FL, Huang $Y H$, Chang $H C$, Huang $C Y$, Lee $M H$ : Cosmetic applications of selected traditional Chinese herbal medicines. J Ethnopharmacol 2006, 106(3):353-359.

15. Solomon El, Chen P, Metz M, Lee SK, Palmer AE: Oxygen binding, activation, and reduction to water by copper proteins. Angew Chem Int Ed Engl 2001, 40(24):4570-4590.

16. Chen P, Solomon El: $\mathrm{O} 2$ activation by binuclear $\mathrm{Cu}$ sites: noncoupled versus exchange coupled reaction mechanisms. Proc Natl Acad Sci U S A 2004, 101(36):13105-13110.

17. Inoue T, Shiota $Y$, Yoshizawa K: Quantum chemical approach to the mechanism for the biological conversion of tyrosine to dopaquinone. J Am Chem Soc 2008, 130(50):16890-16897.

18. Rob D: Tyrosinase. In Copper Proteins and Copper Enzymes. Ilth edition Edited by Lontie R. Florida: CRC Press; 1984:207-240.

19. Tada M, Kohno M, Kasai S, Niwano Y: Generation mechanism of radical species by tyrosine-tyrosinase reaction. J Clin Biochem Nutr 2010, 47(2):162-166.

20. Maeda K, Fukuda M: Arbutin: mechanism of its depigmenting action in human melanocyte culture. J Pharmacol Exp Ther 1996, 276(2):765-769.

21. Funayama M, Arakawa H, Yamamoto R, Nishino T, Shin T, Murao S: Effects of alpha- and beta-arbutin on activity of tyrosinases from mushroom and mouse melanoma. Biosci Biotechnol Biochem 1995, 59(1):143-144.

22. Hori I, Nihei K, Kubo I: Structural criteria for depigmenting mechanism of arbutin. Phytother Res 2004, 18(6):475-479. 
23. Inoue $Y$, Hasegawa S, Yamada T, Date Y, Mizutani H, Nakata S, Matsunaga K, Akamatsu $\mathrm{H}$ : Analysis of the effects of hydroquinone and arbutin on the differentiation of melanocytes. Biol Pharm Bull 2013, 36(11):1722-1730.

24. Lee HJ, Kim KW: Anti-inflammatory effects of arbutin in lipopolysaccharide-stimulated BV2 microglial cells. Inflamm Res 2012, 61(8):817-825.

25. Hisatomi E, Matsui M, Kubota K, Kobayashi A: Antioxidative activity in the pericarp and seed of Japanese pepper (Xanthoxylum piperitum DC). J Agric Food Chem 2000, 48(10):4924-4928.

26. Bang SH, Han SJ, Kim DH: Hydrolysis of arbutin to hydroquinone by human skin bacteria and its effect on antioxidant activity. J Cosmet Dermatol 2008, 7(3):189-193.

27. Baier J, Maisch T, Maier M, Landthaler M, Baumler W: Direct detection of singlet oxygen generated by UVA irradiation in human cells and skin. J Invest Dermatol 2007, 127(6):1498-1506.

28. Pellosi MC, Suzukawa AA, Scalfo AC, Di Mascio P, Martins Pereira CP, de Souza Pinto NC, de Luna MD, Martinez GR: Effects of the melanin precursor 5,6-dihydroxy-indole-2-carboxylic acid (DHICA) on DNA damage and repair in the presence of reactive oxygen species. Arch Biochem Biophys 2014, 557:55-64.

29. Halliwell B, Gutteridge JM: Oxygen free radicals and iron in relation to biology and medicine: some problems and concepts. Arch Biochem Biophys 1986, 246(2):501-514.

30. Dhumrongvaraporn A, Chanvorachote P: Kinetics of ultraviolet B irradiation-mediated reactive oxygen species generation in human keratinocytes. J Cosmet Sci 2013, 64(3):207-217.

31. Nicolay JF, Levrat B: A keratinocytes-melanocytes coculture system for the evaluation of active ingredients' effects on UV-induced melanogenesis. Int J Cosmet Sci 2003, 25(1-2):15-19.

32. Zi SX, Ma HJ, Li Y, Liu W, Yang QQ, Zhao G, Lian S: Oligomeric proanthocyanidins from grape seeds effectively inhibit ultravioletinduced melanogenesis of human melanocytes in vitro. Int $\mathrm{J} \mathrm{Mol} \mathrm{Med}$ 2009, 23(2):197-204

doi:10.1186/1471-2091-15-23

Cite this article as: Tada et al: Alleviation effect of arbutin on oxidative stress generated through tyrosinase reaction with L-tyrosine and L-DOPA. BMC Biochemistry 2014 15:23.

\section{Submit your next manuscript to BioMed Central and take full advantage of:}

- Convenient online submission

- Thorough peer review

- No space constraints or color figure charges

- Immediate publication on acceptance

- Inclusion in PubMed, CAS, Scopus and Google Scholar

- Research which is freely available for redistribution 